\title{
As condutas realizadas por profissionais de saúde em relação à busca de parcei ros sexuais de pacientes soropositivos para o HIV/aids e seus diagnósticos sorológicos
}

\author{
The behaviors carried through for professionals of health \\ in relation the search of sexual partners of patients \\ soropositive for the HIV/aids and its diagnostic serologic
}

Priscilla M esquita Luz ${ }^{1}$

Karla Correa Lima Miranda ${ }^{1}$

Juliana M aria Cavalcante Teixeira ${ }^{1}$

Abstract This article analyzes the performance of the professionals who accompany HIV/aids carrier in the direction to identify which its behavior is face the communication or not of the seropositivity of the patient to its sexual partner in a public service of reference in HIV/aids of the city of Fortaleza, Ceará State. The study is of exploratory character with qualitative boarding. The participants of thestudy were the health professionals of the institution that was accompanying HIV/aids carrier. The collection of the data was made through a half-structuralized interview. The discussions of the data had been made through the Analysis of Content, being possible to identify that the professionals live deeply personal and institutional difficulties, and that they do not feel supported by the institution in relation to the convocation of partners. In this direction, the creation of a protocol for the convocation of the sexual partners becomes necessary.

Key words Professional, Health, Sexual partners, HIV/aids, Diagnostic
Resumo Esteartigo analisa a atuação dos profissionais que realizam o acompanhamento ao portador do HIV/aids no sentido de identificar qual é a sua conduta frente à comunicação ou não da soropositividade do paciente ao seu parceiro sexual no H ospital São J osé de D oenças I nfecciosas, localizado no município de Fortaleza (CE). 0 estudo éde caráter exploratório com abordagem qualitativa. Participaram do estudo os profissionais de saúde da própria instituição que realizavam acompanhamento ambulatorial ao portador do HIV/aids. A coleta dos dados foi feita através de uma entrevista semiestruturada. As di scussões dos dados foram feitas através da análise de conteúdo, sendo possível identificar que os profissionais vivenciam dificuldades pessoais e institucionais e quenão se sentem amparados pela instituição em relação à convocação de parceiros. N esse sentido, faz-se necessária a criação de um protocolo para a convocação dos parceiros sexuais.

Palavras-chave Profissionais, Saúde, Parceiros sexuais, HIV/aids, Diagnóstico
${ }^{1}$ Departamento de Enfermagem, Centro de Ciências da Saúde,

Universidade Estadual do Ceará. Av. Paranjana 1700, Itapery. 60740-000 Fortaleza CE.

priscillaluz@gmail.com 
Introdução

Em meados de 1981, foi apresentada ao mundo uma síndrome que gerava um estado de imunodeficiência mediado por células que ocasionava um quadro de doenças oportunistas em quem ela se instalava. Chamou-se esse agravo de síndromeda imunodeficiência adquirida (aids), causada pelo vírus da imunodeficiência humana (HIV). Essa pandemia causou medo, perda e sofrimento, tornando-se um desafio para a comunidadecientífica mundial ${ }^{1}$.

Há muito tempo a síndrome da imunodeficiência humana deixou de ser um desafio somente para a comunidade científica. A difícil relação estabelecida entrea doença ea população veio mostrar a necessidade do envolvimento multidisciplinar de diferentes segmentos profissionais para, na ausência da cura, procurar deter o crescimento do número de casos e minimizar o quadro de dificuldades queacometem os atingidos pelo HIV.

Os portadores do vírus da aids resgataram significativos direitos civis e políticos; uma demonstração disso foi a Declaração dos Direitos Fundamentais da Pessoa Portadora do Vírus, que trata do direito à informação, à assistência e ao tratamento, como também da discriminação, da participação em todos os aspectos da vida social, entre outros assuntos. $M$ as os dois pontos mais marcantes são a privacidade do portador do vírus e 0 direito de comunicar apenas às pessoas que deseja o seu estado de saúde ou o resultado dos seus exames². Entretanto, de acordo com 0 artigo 105 da resolução $n^{\circ}$ 1.359/92 do Conselho Federal de M edicina, será permitida a quebra de sigilo por justa causa (proteção à vida de terceiros, incluindo-se os comunicantes sexuais) quando o próprio pacienterecusar-sea fornecer-Ihesa informação quanto a sua condição de infectado.

Acredita-se que um dos momentos no qual 0 profissional de saúde poderá estabelecer uma relação de confiança com seu paciente seria durante 0 aconselhamento, no qual se visa resgatar através dos recursos internos do profissional a possibilidade do cliente se reconhecer como sujeito de sua própria saúde e transformação.

0 processo deaconselhamento, especialmente no âmbito do HIV/aids, tem como componentes 0 apoio emocional, o apoio educativo, que trata de informações sobre HIV/aids e suas formas de transmissão, prevenção e tratamento e, por último, a avaliação de riscos, que propicia a reflexão sobre valores, atitudes e condutas, incluindo o planejamento de estratégias de redução de risco ${ }^{3}$. Este éum momento de grandeim- portância, no qual o profissional de saúde poderá interagir com o cliente, facilitando o diálogo e discutindo a necessidade de convocar sua parceria sexual.

A convocação do parceiro sexual do paciente soropositivo é imprescindível para que assim ele possa procurar assistência institucional para investigação de sua condição sorológica, quebrando uma possível cadeia de transmissão do HIV, mas percebe-se certo receio dos profissionais de saúde a respeito dessa problemática. Até onde pode-se manter a privacidade e sigilo do portador do vírus da aids e omitir sua soropositividade, colocando em risco outras pessoas? Será que os parceiros sexuais dos portadores do HIV são convocados à testagem também? Como se dá essa convocação?

Portanto, diante de tais questionamentos, 0 estudo proposto chama a atenção dos profissionais na tentativa de alertá-los para essas reflexões. Desta forma, este estudo tem como objetivo verificar e analisar as condutas realizadas por profissionais de saúde em relação à busca de parceiros sexuais de pacientes soropositivos para 0 HIV/aids e seus diagnósticos sorológicos. Os achados da pesquisa podem possibilitar aos profissionais que fazem aconselhamento em HIV/ aids a dialogar ediscutir com outro ol har as condutas e encaminhamentos em relação à parceria sexual de pessoas com HIV/aids. Esses parceiros poderão assim ser beneficiados com relação ao acesso ao serviço de saúde e suas condutas de promoção da saúde. Também pretende-se que os serviços de saúde tomem consciência dessa problemática e comecem a encontrar maneiras de promover uma busca efetiva dos parceiros sexuais dos pacientes soropositivos, daí a relevância desteestudo.

\section{Metodologia}

Trata-se de um estudo descritivo/exploratório com abordagem qualitativa, no qual sepodecontemplar a subjetividade dos profissionais que realizam o acompanhamento ao portador do HIV no sentido de perceber qual éa sua conduta frente à decisão do paciente de comunicar ou não ao parceiro sexual a sua condição de portador do vírus da aids.

A pesquisa foi realizada no H ospital São José deDoenças Infecciosas, localizado no município deFortaleza (CE). A escolha do local da pesquisa deveu-se ao fato de ser referência para 0 atendimento aos portadores de HIV/aids no Estado do 
Ceará e por ter acompanhamento multiprofissional dessa clientela.

Participaram do estudo os profissionais de saúde que realizavam acompanhamento ambulatorial ao portador do HIV/aids. 0 número desses profissionais entrevistados dependeu da aceitação em participar da pesquisa e do critério de saturação teórica, quando as experiências e percepções estavam se repetindo, totalizando um número de doze entrevistas. Destes, dois eram assistentes sociais, dois psicól ogos, três enfermeiros e cinco médicos. As entrevistas foram numeradas por ordem de realização e cada número recebeu um nome bíblico, respeitando assim a confidencialidade dos entrevistados.

As entrevistas foram gravadas para possibilitar maior interação entre a pesquisadora e seu entrevistado. Entretanto, três depoentes não permitiram a utilização do gravador pela pesquisadora. Também foi feita observação direta na realização dos atendimentos dos profissionais durante a consulta ao soropositivo para HIV, variando segundo a permissão do profissional e disponibilidade da pesquisadora. Segundo Polit ${ }^{4}$, a observação direta permite a obtenção de muitas espécies de informações, necessárias aos pesquisadores, ou como indicações de aperfeiçoamento das práticas de saúde. Durante a observação das consultas, foram feitas anotações em campo que, segundo Polit,",representam os esforços do observador participativo, no sentido de registrar as informações, sintetizar e compreender os dados".

As discussões dos dados foram apresentadas através da análise de conteúdo que, de acordo com M inayo ${ }^{5}$, éa expressão mais comumente utilizada para representar uma pesquisa qualitativa. Sendo que o termo trata de uma busca teórica e prática no campo das investigações sociais e não somente um procedimento técnico.

As entrevistas foram transcritas de maneira fidedigna. A análise dos dados foi composta por três momentos: pré análise, exploração do material e tratamento dos resultados, inferência e interpretação. A pré-análise foi a fase de organização do material propriamente dita. N essa fase, fez-se a codificação do material, que correspondeu a uma transformação dos dados brutos do texto através de recorte, agregação e enumeração, para atingir uma representação do conteúdo e de sua expressão, susceptível de esclarecimento das características do texto.

A pós a leitura exaustiva dos textos e a marcação das unidades de registro, passou-se para a categorização desses dados. A categorização éuma operação de classificação deelementos constituti- vos deum conjunto, por diferenciação e, seguidamente, por reagrupamento segundo o gênero com os critérios previamente definidos. As categorias são classes as quais reúnem um grupo de elementos (unidades de registro) sob um título genérico, agrupamento esse efetuado em razão dos caracteres comuns destes elementos. As anotações em campo foram usadas para contextualizar, negar ou confirmar as informações que se obteve dos discursos dos profissionais ${ }^{6}$.

0 agrupamento dasunidades de registro através de semelhanças e significados entre si deu origem a três categorias temáticas discutidas a seguir e a análise das falas foram comentadas à luz do referencial teórico de Paulo Freire.

A participação dos profissionais na pesquisa foi voluntária e teve-se o cuidado de esclarecê-los quanto aos objetivos da pesquisa e às contribuições desta, formal izando o consentimento livree esclarecido, de acordo com os critérioséticos para pesquisas que envolvem seres humanos, conforme a Resolução no 196/96 do Conselho Nacional deSaúde/M inistério da Saúde 7 . 0 projeto foi submetido e aprovado pelo Comitê de Ética em Pesquisa do Hospital São José de D oenças I nfecciosas. Os recursos disponíveis para a pesquisa foram oriundos da Fundação Cearense de Apoio ao Desenvolvimento Científico e Tecnológico (FUNCAP).

\section{Discussão eanálisedos dados}

\section{Caracterização dos sujeitos}

Quanto à titulação do grupo estudado, oito eram especialistas eum, mestre. 0 tempo médio de formado foi de aproximadamente dezesseis anos, variando de 6 a 29 anos. E o tempo médio de atuação em atividades voltadas para 0 HIV/ aids foi de aproximadamente sete anos, variando de três a dezenove anos. Quanto ao gênero, dez mulheres e dois homens foram entrevistados; destes, seis eram casados, três eram divorciados, dois eram solteiros e um, viúvo. A média de idade foi de aproximadamente 41 anos, variando de 29 a 59 anos.

Emergiram neste estudo três categorias. A primeira denominou-sede "Sentimentos relacionados ao HIV/aids"; essa categoria se refere aos sentimentos dos profissionais em relação a sua vivência com o HIV/aids; a segunda categoria, nomeada de "Dificuldades enfrentadas pelo profissional de saúde", refere-se às dificuldades enfrentadas no atendimento e convívio com o pa- 
ciente portador do HIV/aids e a terceira categoria chamou-se de "Estratégias realizadas pelos profissionais de saúde"; essa estratégia é de superação dos sentimentos e das dificuldades.

\section{Sentimentos relacionados ao HIV/aids}

Os sentimentos destacados em dois momentos foram os sentimentos do cliente, percebido pelos profissionais de saúde durante os atendimentos, e os sentimentos dos profissionais em relação a sua prática junto a esses pacientes. É importante deixar claro queexistem três tipos de atendimentos: 0 aconselhamento, que é 0 atendimento de oferecimento da testagem anti-HIV, em que se oferece suporte educacional, emocional e avaliação de vulnerabilidades, sendo realizado por enfermeiros, psicólogos e assistentes sociais; as consultas oficialmente institucionalizadas, que são a médica e de enfermagem; e, por último, os atendimentos interdisciplinares para entrega de preservativo, que são realizados por enfermeiros, psicólogos e assi stentes sociais.

Os sentimentos do paciente percebidos pelo profissional de saúde durante as consultas de acompanhamento são de muita dor, pois é muito difícil o recebimento do exame positivo para o HIV pelo paciente. Esse diagnóstico está fortemente ligado ao sentimento de medo da morte, do preconceito, da rejeição, do rompimento das relações edo medo deter queenfrentar tudo isso.

É fundamental destacarmos que o profissional não está imune aos sentimentos trazidos pelo paciente; toda a história de vida do cliente afeta em alguma medida o profissional. Entretanto, é importante que o profissional tenha um cuidar ético, não se deixando tomar por sentimentos de penalização, muitas vezes paralisantes frente ao clienteeà gama de sofrimentos queele passa, pois no momento que isso ocorre, o profissional se despotencializa, talvez minimizando sua capacidade ética e desconsiderando o cuidado ao outro.

Paulo Freire propõe uma nova concepção da relação pedagógica que pode se estender para a relação profissional desaúde-cliente, na qual não setrata de conceber a relação apenas como transmissão de conteúdo por parte do profissional. Pelo contrário, trata-se de estabelecer um diálogo. Isso significa queaquele que educa está aprendendo também ${ }^{8}$.

0 profissional deve estar sempre buscando um atendimento reflexivo, com uma proposta dialogal que permita ao paciente falar de seus problemas, suas inquietações, possibilitando a percepção da gravidade que repercuteo diagnós- tico de infecção pelo HIV em múltiplos aspectos da vida do paciente e da sua família, sobretudo quando se tem em vista a carga de desconhecimento, incompreensão e preconceito que ainda cerca essa patologia. 0 profissional desaúde deve, através de um diálogo problematizador, pensar qual a melhor maneira de lidar com os sentimentos do cliente, já que é impossível não ser submetido a eles durante 0 atendimento ao portador do HIV/aids.

Para Paulo Freire 9 , a educação problematizadora está fundamentada na criatividade e estimula uma ação e uma reflexão verdadeiras sobre a realidade, respondendo assim à vocação dos homens que não são seres autênticos senão quando se comprometem na procura e na transformação criadoras 9 .

0 profissional que atende ao portador do HIV/aids pode se deparar com aspectos do atendimento nos quais ocorrem obstáculos, barreiras que precisam ser vencidas. Essas barreiras são chamadas por Paulo Freire ${ }^{10}$ de "situaçõeslimite". Os profissionais têm várias atitudes diante dessas situações-limites: ou as percebem como obstáculo que podem transpor, ou como algo que não querem transpor ou ainda como algo que sabem que existe e que precisa ser rompido e então se empenham na sua superação. Isso é percebido em relação à superação dos sentimentos que 0 atendimento ao portador do HIV/aids remete ao profissional ${ }^{10}$. Vejamos a fala a seguir: De certa forma temos quecriar uma espé cie de escudo protetor para não nos envolvermos emocionalmente e acabar sofrendo e não conseguindo resolver os problemas dos pacientes. $\mathrm{Na}$ medida do possível, acabamos tentando ser o mais profissional possível. 0 envolvimento busca ser profissional edeajuda. Essa éa função do profissional de saúde. É lógico que com alguns pacientes acabamos nos envolven do mais, masisso acaba estragando a relação médico-paciente. ( $M$ alaguias)

Oliveira et al. ${ }^{11}$ ratificam a fala acima quando afirmam que os profissionais consideram o portador de HIV/aids como um usuário social, econômica e culturalmente menos favorecido, eque alguém deve ampará-lo, eessealguém acaba sendo os próprios profissionais. De certa forma, cria-se uma relação de vínculo entre eles, o queé muito bom para a manutenção do diálogo mas, por outro lado, abre espaço de maneira informal para a dependência dejuízos evontades pessoais, sobretudo por partedos profissionais. Essa criação de juízo de valores a respeito do paciente é reconhecida pelos profissionais, mas é vista de maneira bastante prejudicial para a relação pro- 
fissional-paciente. Então, como modo de evitar o surgimento dessa informalidade, eles preferem se manter numa postura de neutralidade em relação a seu atendimento e ao envolvimento com os pacientes, mas essa neutralidade pode causar um distanciamento, pois o que caracteriza o cuidado no sentido pleno da palavra não é a simples preocupação com o biológico, por mais que seja cuidadosa a delimitação desse cuidado biológico. Cuidar é perceber etrabal har com a efetiva presença de um sujeito diante do outro. Realizando mesmo a possibilidade dessa mútua presença, encontra-se sim, um cuidar, objetivo do envolvimento profissional desaúde-paciente, que érealizado através de uma interação, de um diálogo entre sujeitos ${ }^{12}$.

Desta forma, pensamos que o sujeito profissional não necessita aniquilar o sujeito-paciente, nem paralisar frenteao sofrimento do outro. Fazse necessário que o profissional de saúde esteja sempre se posicionando criticamente e não se afastando do contato com o outro como forma de autoproteção.

A relação crítica considera os homens como seres inacabados, incompletos em uma realidade igualmente inacabada e o caráter inacabado dos homens juntamente com o caráter evolutivo da realidade exigem que a relação profissionalcliente seja uma atividade contínua. A relação é, deste modo, continuamente refeita pela práxis ${ }^{9}$.

0 distanciamento deal guns profissionais nas questões psicossociais dos pacientes é comprovado pelas falas a seguir: Eu falo na primeira consulta que ele traga seu parceiro sexual, se ele não trouxer na próxima, eu encaminho para o serviço social, ou enfermeira ou psicóloga. Eles resolvem isso. 0 nosso tempo já é tão pouco. (M alaguias)

$\mathrm{N}$ ão encontro dificuldade de abordar o paciente sobre a convocação dos parceiros. 0 problema quevejo, por isso encaminho para os outros profissionais, é mesmo o contato. U ma coisa é dizer traga seu parceiro e outra coisa é ele vir. Existem vários problemas que precisam ser acompanhados mais de perto. (José)

Tendo em vista que o cuidar de pessoas com a síndrome da imunodeficiência adquirida passa a fazer parte do dia a dia demuitos profissionais da área da saúde, é fundamental o resgate da verdadeira essência desse cuidado, para possibilitar maior amorosidade entre os seres humanos e, com isso, desvelar um mundo com mais valor, valor esse presente nos preceitos éticos necessários para se viver em comunidade e, nessa vida em comunidade, épreciso que exista a solidariedade, qualidade essencial para se enxergar as necessida- des do outro, principalmente se esse outro é portador deuma doença estigmatizantecomo a aids ${ }^{13}$.

Para Paulo Freire ${ }^{14}$, não há educação sem amor. 0 amor implica luta contra o egoísmo. Quem não écapaz deamar os seres inacabados não pode educar. N ão há educação imposta, como não há amor imposto. Quem não ama não compreendeo próximo, não o respeita.

0 cuidado ao pacientesoropositivo exigeque o profissional o veja como um ser humano, com suas necessidades básicas afetadas, encontrando-sefragilizado, portanto, merecendo mais respeito eatenção. É fundamental que os profissionais exercitem 0 autocuidado desses pacientes com o objetivo de incentivarem sua autonomia e autoestima.

É importante salientar que a relação entre profissional epacienteproposta aqui éuma relação tal que permita ao profissional entrar efetivamente em contato com as questões da subjetividade, levando em consideração os aspectos social, cultural, afetivo e simbólico, proporcionando uma qualidade de vida na qual o foco não seja centrado apenas no biológico, mas na escuta e no diálogo reflexivo e problematizador.

Dificuldades enfrentadas

pelo profissional de saúde

Essa categoria possui três questões-chave: dificuldades do cliente, institucionais e pessoais do profissional. 0 primeiro ponto é justamente a dificuldade que 0 profissional enfrenta para abordar o paciente por conta de toda a demanda de sentimentos decorrentes do diagnóstico positivo para o HIV. 0 profissional passa a se fragilizar com os sentimentos do cliente e desenvolve mecanismos de ajuda, de pena, de proteção ao paciente, e nesse momento há um bloqueio do profissional, podendo impedir que ele faça uma abordagem problematizadora em que o paciente também faça parte das discussões. A fala abaixo demonstra bem isso: Eu sinto que as histórias de vida que os pacientes portadores do HIV/aids trazem são sempre muito difíceis e dolorosas, e não temos como ficar ileso disso, sempre me coloco no lugar deles e vejo como é muito difícil tudo o que eles passam. Isso me paralisa um pouco. ( $M$ arcos)

É preciso que o profissional encontre maneiras de superar essas dificuldades e consiga manter uma postura ética, sem perder a noção do queédo pacienteedo queéseu como pessoal, no qual o sentimento de pena e o de proteção ao paciente não superem a importância da convocação dos parceiros sexuais. 0 que dificulta ain- 
da mais a superação dessas dificuldades é a falta de uma participação efetiva da instituição neste fato, pois ela não oferece aos profissionais meios adequados para que eles a superem. Vejamos 0 que diz o discurso abaixo: Realmente enquanto estamos aqui recebemos uma carga muito pesada de sentimentos muito fortes. Eu acho que o profissional tem queter uma válvula deescapepara isso. Infelizmente não temos um suporte interno, da instituição, decuidados para os profisssionais. Acaba sendo uma coisa individual. (Lucas)

A dita "falta de apoio" da instituição não pode ser modificada, enquanto os profissionais desaúde não descobrirem que é modificável, que eles podem fazêlo. Se faz necessário que os profissionais se articulem, discutam sobre o assunto e em um pensamento unificado tracem estratégias, sempretendo em vista as condições da instituição para que essas estratégias sejam implementadas.

$N$ ão só a falta de apoio às dificuldades pessoais dos profissionais foram citadas nas entrevistas, mas o não interesse pela busca do cliente que não vem receber o exame do anti-HIV, a não busca por pacientes soropositivos que não comparecem às consultas e desaparecem do serviço, além da falta de um protocolo para a realização da convocação de parceiros; esses fatos foram denominados dificuldadesinstitucionais: Eu nunca vi uma preocupação da instituição em relação à busca de pacientes e de seus parceiros. Nós temos uma demanda espontânea de pessoas que vêm fazer o exame anti-HIV e muitas delas não vêm pegar o resultado. A maioria das pessoas que vêm fazer o exame aqui é porque tiveram alguma vulnerabilidade, ninguém sai de casa para ir a um hospital fazer um exame se não achar que correu al gum risco e as chances de ser positivo são muito altas. M esmo assim a instituição não se preocupa em ir atrás desse paciente. 0 que vejo é que o hospital está mais preocupado com o atendimento aos pacientes que estão vindo ao serviço. (Pedro)

Essa falta de apoio da instituição pode ter vários motivos: falta de estrutura física do hospital, de recursos humanos, alta demanda de pacientes ocasionando pouco tempo para as consultas, falta de uma organização do serviço que permita que os profissionais tenham uma abordagem ética do paciente.

Porém, vale ressaltar a grande demanda de pacientes que o serviço estudado comporta, decorrente, além de outros fatos, do preconceito e do medo ainda existentes por parte da população em procurar os serviços de atenção básica para aconselhamento e solicitação da testagem sorológica para o anti-HIV. Esses clientes, mui- tas vezes, não recebem o resultado do seu exame por dificuldade de deslocamento atéo serviço de referência, já que geralmente não são próximos do seu trabalho ou residência.

Ampliar o acesso e a oferta do teste anti-HIV e do aconselhamento para a população é uma importante estratégia para a prevenção da disseminação do vírus HIV ${ }^{15}$, na qual a atenção básica é um campo propício para a ampliação desse serviço. Pois o aconsel hamento éuma prática que se assemelha aos princí pios adotados na atenção básica, no sentido dese propor a resgatar o modo como se dá o relacionamento entre o serviço e seususuários, enfatizando o caráter preventivo e a articulação com a prática assistencial.

Outra dificuldade institucional citada foi a falta de continuidade das condutas realizadas; isso édecorrentejustamente da não existência de um protocolo que permita que o profissional tenha um controle do paciente, que o permita saber se o paciente trouxe seus parceiros ou fiIhos para fazer o exame anti-HIV. Podemos confirmar isso através da fala a seguir: Não temos uma convocação de parcei ros de forma sistematizada, organizada. 0 quefazemosrealmenteépedir para os pacientes que tragam seus parcei ros sexuais e seus filhos, mas na realidade não sabemos se estão vindo. Não temos o controle. (Pedro)

Trabalhar com convocação de parceiros não é fácil, pois essa abordagem é permeada de dilemas éticos que podem nos barrar, nos paralisar. A fala abaixo deixa claro o dilema do profissional, que se vêdesamparado pelainstituição em termos da existência de um protocolo e tendo a necessidade de fazer a convocação de parceiro: Como vou me comunicar com esse parceiro? Porque isso é complexo, às vezes a pessoa não tem telefone, a única maneira dese comunicar épor telefone público. Tinha queter um contato com a pessoa, o soropositivo teria que dar o nome e o telefone, se ele mesmo não quisesse revelar. N esse caso, de ele não querer comunicar e continuar com esse parceiro, o contaminando, teria que haver essa intervenção. (M atheus)

Paulo Freire ${ }^{16}$ argumentava a favor da necessidade de uma prática que defenda a "ética universal do ser humano", ética enquanto marca da natureza humana, enquanto algo absolutamente indescritível à convivência humana. Há uma necessidade de uma discussão em maior proporção sobre os dilemaséticos, principal mentequando se fala em convocação de parceiros sexuais de pacientes soropositivos para o HIV.

Além das dificuldadesinstitucionaise do cliente, os profissionais ainda têm que superar as dificuldades pessoais. Essas dificuldades referem-se 
aos questionamentos dos profissionais, ao modo como abordar o paciente: A pós falar sobre contar para os parceiros, a pessoa diz: "N ão é o momento porque ele vai me matar se eu disser". Aí fica muito difícil eu intervir dizendo: "Você tem que falar". Falamos da importância. 0 problema que vejo é falar isso naquelemomento edepoisnão poder acompanhar essa pessoa. Porque têm situações que não tenho como avaliar o risco para o paciente. Se ele diz: "Eu vou falar e elevai espalhar para todo mundo e vai ser pior para mim", aí eu penso em uma próxima consulta tocar de novo no assunto, mas não sei sevou ter uma próxima consulta com ele. $\mathrm{E}$ acho que não funciona atitudes rigorosas. Temos limitações no que colocamos. (Lucas)

0 profissional está desamparado nesse momento, por não haver um protocolo de convocação de parceiros e por não haver uma organização do serviço que proporcione ao profissional uma abordagem segura de seu paciente, na qual a avaliação de risco seja possível. M ais uma vez, o profissional encontra-se frente a uma situação-limite em que deverá decidir qual a melhor conduta a realizar.

Frente a todas as dificuldades sofridas pelos profissionais e as possibilidades de enfrentamento, podemos citar um conceito proposto por Paulo Freire ${ }^{10}$, que diz: 0 "inédito-viável" é na realidade uma coisa inédita, ainda não claramente conhecida e vivida, mas sonhada e quando se torna um "percebido destacado" pel os que pensam utopicamente, esses sabem, então, que o problema não é mais um sonho, que ele pode se tornar realidade.

Esse conceito ébase de reflexão de seres pensantes e preocupados em superar as situaçõeslimite, proporcionando assim um atendimento de qualidade e um crescimento pessoal, quer dizer, apesar da instituição não favorecer nem fisicamente, nem apoiando o profissional, faz-se necessário pensarmos em estratégias realizáveis que possibilitem a convocação e o cuidado ético para os clientes e seus parceiros.

Estratégias realizadas

pelos profissionais de saúde

Essa categoria foi dividida em dois momentos: no primeiro, discutiremos as estratégias realizadas no cotidiano do atendimento dos profissionais e, no segundo, falaremos das estratégias idealizadas pel os profissionais para superação das dificuldades encontradas.

A entrega da sorologia anti-HIV éo momento mais difícil para o profissional epara o cliente, pois esses estarão se deparando com a possibili- dade da morte, do desconhecido, do abandono e do preconceito, daí a dificuldade de abordar o tema de convocação de parceiros. Vejamos a seguintecitação: Quando atendo uma consulta pósteste de resultado positivo, já abordo sobre parcerias sexuais e peço queas traga no dia de sua primeira consulta médica, mas isso vai variar dependendo de como o paciente reagiu durante a revelação da condição sorológica. (Thiago)

Percebemos nas entrevistas e através da observação da rotina do serviço que o primeiro contato do paciente com a temática convocação de parceiros poderá ser durante 0 aconselhamento pós-teste ou na primeira consulta médica ou de enfermagem. Essas consultas são marcadas após a realização do aconselhamento, tendo dois resultados positivos para o exame do anti-HIV. 0 que determina o momento de abordar 0 assunto das parcerias sexuais éa reação do paciente frente à descoberta de sua condição sorológica.

Nesse contexto, percebemos a importância de uma abordagem multidisciplinar einterdisciplinar no aconselhamento, permitindo que 0 paciente fale sobre seus sentimentos e dúvidas, obtenha orientações e esclarecimentos acerca do assunto: Por conta de todas as dificuldades que 0 paciente vem passando, me sinto na obrigação de ajudar, e tento fazer isso através de um aconsel hamento bem feito, escutando o paciente, se disponibilizando na tentativa de fazer o paciente se sentir acolhido. (J oão)

A inter etransdisciplinaridade abordados por Paulo Freire não são apenas um método pedagógico ou uma atividade do profissional. Eles se constituem uma verdadeira exigência da própria natureza do ato pedagógico ${ }^{17}$. Muitos profissionais utilizam algumas estratégias que facilitam essa convocação dos parceiros pelo paciente, como mandar comunicados para que os pacientes entreguem a seus parceiros: Como é que faço hoje. Atendo a pessoa, converso, sempresensibilizo para a importância de comunicar o parceiro. E até envio por escrito um comunicado para que o paciente entregue a seu parceiro, mas não faço com todos, pois não tenho o controle disso. (Lucas)

A maioria dos profissionais de saúde se disponibilizam a estar junto, ajudando no momento da revelação, prática benéfica ao serviço e ao paciente, pois proporciona apoio ao paciente e um vínculo de confiança entre ambos: No momento da consulta, falo da necessidade de comunicar ao parceiro sua condição sorológica, falo deuma maneira sem forçar. Não precisa que ele chegue em casa, corra etraga o parceiro aqui, tem o momento para pensar, para refletir, um momento para ama- 
durecer, mas não pode demorar muito, passar não sei quanto tempo para dizer. Claro que tem o momento para refletir a maneira como vai dizer, como revelar. E eu me ofereço, como também muitos se oferecem, nos disponibilizamos a ajudar, até contar se ele quiser ou tiver dificuldade. (M atheus)

A ética difundida por Freire consiste na busca consciente da coerência entre o discurso e a prática, na luta por uma ética democrática, compreendendo a função social do educador/profissional de saúde progressista a favor de um projeto social mais amplo, assumindo as opções que orientam sua prática ${ }^{18}$. A grande maioria dos profissionais entrevistados afirmou conhecer 0 direito que o parceiro tem de saber sua condição sorológica e o direito ao acompanhamento de sua saúde pelo serviço hospitalar. A pessoa soropositiva tem dever de proteger seus parceiros sexuais, comunicando sua condição sorológica e usando preservativo em todas as relações sexuais. Esse conhecimento do direito do parceiro sexual muitas vezes é usado pelo profissional como forma de obrigar o paciente a comunicar ao seu parceiro sua condição sorológica. As seguintes frases mostram isso: Q uando não consigo convencer o paciente da necessidade de trazer 0 parceiro para fazer o exame, falo das complicações jurídicas elegais de elenão contar, pois estará colocando em risco a vida dessa pessoa que el e gosta eo privando de se tratar. ( João)

Temos que ponderar as consequências da reve lação. Podem ser consequências graves, como abandoná-lo, mas o parceiro tem direito a saber. 0 paciente não pode permanecer com esse parceiro sem que ele tenha direito de se tratar. (Jacó)

A coerção parece não ser uma opção educativa, devemos tentar através do diálogo, da sensibilização mostrar ao pacienteque o outro tem os mesmo direitos a tratamento que ele, pois o cuidar ético no contexto das doen çasinfecciosas deve ser sempre pensado numa perspectiva problematizadora. Devemos estar atentos ao desenvolvimento de uma prática profissional com uma competência técnica, isto é, o saber fazer, o para quê, o porquê e o como fazer; entretanto, não basta que o profissional tenha esse domínio técnico. É fundamental um saber cuidar ético, levar em conta a vida e defendêla, considerando a necessidade do cliente, mas sem julgá-lo, discriminá-lo ou estigmatizá-lo, sem perder de vista o cuidado ao outro. É articular liberdadee responsabilidade, liberdade no sentido da ação assumindo a responsabilidade frente a seus atos.

0 pensamento crítico se apresenta como condição para o diálogo e, ao mesmo tempo, o diá- logo aparece como único capaz de gerar o pensamento crítico, de promover a comunicação e garantir a verdadeira educação ${ }^{19}$. Ao contrário desse grupo, existe outro que não se envolve com questões ligadas à subjetividade do paciente, não se identificando com a problemática de convocação de parceiros; geralmente, esse grupo encaminha o paciente para que outros profissionais façam essa abordagem. Isso fica claro no depoimento a seguir: Tentamos, na medida do possível, orientá-los para trazer seus parceiros, mas encaminho para o pessoal do aconselhamento para fazer uma abordagem mais profunda. Faço isso na primeira consulta, nas subsequentes não questiono muito 0 assunto. Pergunto se está usando preservativo e até quando detecto problemas nesse aspecto encaminho para o pessoal da psicologia, do serviço social. (José)

Por meio desse depoimento, podemos perceber que ainda temos uma divisão do trabal ho do profissional de saúde em que o pensamento cartesiano defineas práticas das categorias profissionais, fragmentando e multifacetando o sujeito atendido.

Dessa forma, percebemos em todas as entrevistas a necessidade da organização de um serviço ou protocolo que facilite o processo de convocação de parceiros, possibilitando que o profissional tenhaum controledesse pacienteem relação à adesão ao tratamento e principalmente comunicação aos parceiros sexuais: Tinha queter um serviço montado de convocação de parceiros. A instituição tinha que dar todo apoio de recursos humanos, recursos materiais e financeiros. ( $M$ atheus)

Uma questão bastante citada nas entrevistas pelos profissionais não médicos foi a necessidade de realização de encontros sistemáticos da equipe. Isso proporcionaria dois benefícios: o primeiro seria a possibilidade de tornar esses momentos encontros terapêuticos nos quais o profissional pudesseexpor suas dificuldades e seus questionamentos e o segundo benefício seria a possibilidade de discussão dos casos entre a equipe. Isso geraria um processo de interdisciplinaridade, facilitando a realização da convocação de parceiros: A instituição deveria criar espaços em que pudéssemosfalar sobreos nossos sentimentos, falar sobreas nossas dificuldades. A equipe de aconselhamento ainda não tem reuniões sistemáticas que permitissem que falássemos sobre os pacientes, possibilitando assim que todos o conhecessem e pudéssemos marcar o retorno dele para qualquer profissional, assim poderíamos aproveitar o dia que el viesse ao hospital para fazer exames ou para consulta médica para atendê los também. (Lucas) 
“O diálogo é o momento em que os homens se encontram para refletir sobre a sua realidade tal como a fazem e refazem", afirma Damke ${ }^{20}$. A função do diálogo é desencadear a atividade intelectual do sujeito e desafiá-lo a penetrar em níveis cada vez mais profundos e mais amplos do saber, a fim de encontrar as respostas necessárias às questões que se colocam ${ }^{19}$. Cinco profissionais relataram nunca ter pensado como a convocação de parceiros poderia estar sendo realizada. Esse dado é preocupante, pois essa deveria ser uma inquietação insistentena vida desses profissionais, já que el es passam por essa dificuldade no cotidiano dos seus atendimentos.

É importante ressaltar que já existe um modelo de convocação de parceiros utilizado nos atendimentos nas doenças sexualmente transmissíveis (DST). Esse modelo já funciona nos ambulatórios que atendem essa patologia. Os atendimentos são bem estruturados e contam com financiamento de instituições também não governamentais, nos quais são realizados grupos de estudos, cursos de atual ização, seus participantes participam de congressos e encontros regularmente. Entretanto, parece existir um hiato lamentável entre as instituições tanto governamentais quanto não governamentais, no sentido de não compartilhar informações, tecnologias e saberes. Coadunamos com Freire ${ }^{9}$ quando el e nos fala que o conhecimento não tem nenhuma valia sem ser compartilhado e socializado.

Vale ressaltar que cada patologia tem um itinerário peculiar equestões simbólicas singulares que devem ser particularizadas. No caso da aids, existem vários signos e significados próprios na construção do imaginário popular acerca dessa patologia. É de fundamental importância que os serviços estejam acompanhando e possibilitando ao profissional desenvolver estratégias para a minimização dos problemas e conflitos do paciente, para que este se sinta menos abandonado e mais acolhido em suas inquietações.

Podemos perceber que a aids trouxe pontos éticos bastante delicados, pois surgiu da necessidade de balancear os direitos e as necessidades do indivíduo e do bem público. Os códigos de ética dos profissionais de saúde aparecem nesse contexto como uma forma de nortear as condutas frente aos problemas éticos, sempre tendo em vista os princípios da confidencialidadeeprivacidade da condição sorológica do paciente, mas eles também respaldam o profissional quanto à quebra de sigilo no momento que esse paciente, deliberadamente, estiver pondo em risco a saúde de outras pessoas.
Assim, surge a necessidade dos profissionais conhecerem seus códigos deética, discutirem seus pontos de fragilidade, com o objetivo de assegurar os mesmos direitos à saúde a todos os sujeitos, independente de qualquer variável que possa remeter à exclusão e à discriminação.

\section{Consideraçõesfinais}

Podemos referir que a temática escolhida é muito complexa, tendo em vista todo nosso contexto cultural, social, político eeconômico, mas existe 0 interesse de al guns profissionais por ela. Pudemos perceber a importância da convocação dos parceiros sexuais como uma das formas de quebra da cadeia de transmissão do vírus do HIV e com possibilidade de um atendimento e acompanhamento especializado, possibilitando uma maior sobrevida do parceiro sexual.

É necessária a criação de um protocolo que permita que o profissional faça a convocação dos parceiros, tendo como dar continuidade as suas condutas etenha um controle seesse pacienteestá voltando ao serviço com seu parceiro sexual. Dessa maneira, o profissional sesentirá respaldado pela instituição em relação as suas decisões.

A equipe que atende os clientes portadores do HIV/aids precisa estar mais coesa, colocando em prática conceitos como interdisciplinaridade, referência e contrarreferência. Sugerimos que os profissionais marquem reuniões sistemáticas nas quais eles possam discutir os casos mais complicados ou os que eles tenham al gum problema ou dúvida na conduta. Isso possibilitaria que o profissional se sentisse mais seguro e apoiado pela equipe frente as suas decisões.

Sugerimos quedurantea consulta para entre ga de preservativos fosse o momento ideal para reforçar uma conversa efetiva e problematizadora sobre o assunto com o paciente. Essa consulta não é muito valorizada pelo profissional, mas é esse o momento que o profissional pode manter um vínculo com o paciente, questionando sobre sua sexualidade, adesão, como também sobre a comunicação de sua parceria sexual.

Defendemos ser esse o momento oportuno, pois já existe disponibilizado o nomede todos os pacientes que recebem preservativos com o número do prontuário. Seria esse momento ideal para fazermos as anotações necessárias e um acompanhamento mais sistematizado.

Para que a comunicação do parceiro sexual em HIV/aids se torne realidade, se faz necessário o diálogo permanente entre as instituições não 
governamentais, governamentais, profissionais de saúde, gerência institucional. Juntos, poderão somar forças no intuito de fazer da convocação do parceiro também um momento educativo para além do pragmatismo e da atividade profissional descomprometida com a transformação do sujeito.

\section{Referências}

1. Farthing CF, Simone EB, Richard CDS. Atlas colorido de aids e da doença do HIV. $2^{a}$ ed. Porto Alegre: Artes M édicas; 1989.

2. Brasil. M inistério da Saúde. Manual de diretrizes técnicas para elaboração e implementação de programas de prevenção e assistência das DST/aids no local de trabalho. Brasília: Ministério da Saúde/Coordenação Nacional de DST e Aids; 1998.

3. Brasil. M inistério da Saúde. Aconselhamento em DST, HIV e aids. Diretrizes e procedimentos básicos. 3a ed. Brasília: M inistério da Saúde/Coordenação N acional de DST e Aids; 1999.

4. Polit DF, Hungler BP. Fundamentos de pesquisa em enfermagem. 3a ed. Porto Alegre: Artes M édicas; 1995.

5. M inayo MCS. 0 desafio do conhecimento: pesquisa qualitativa em saúde. 7ạa ed. São Paulo: Hucitec; Rio de Janeiro: Abrasco; 2000

6. Bardin L. Análise de conteúdo. Lisboa: Edições 70 1977.

7. Brasil. Conselho Nacional de Saúde. Resolução n 196/96. Dispõe sobre diretrizes e normas regulamentadoras de pesquisas envolvendo seres humanos. Bioética 1996; 4(Supl. 2):15-25.

8. Gadotti M. U m legado de esperança. São Paulo: Cortez; 2001.

9. Freire P. Conscientização: teoria e prática da libertação - uma introdução ao pensamento de Paulo Freire 3a ed. São Paulo: Moraes; 1980.

10. Freire AM AF. Notas. In: Freire P. Pedagogia da esperança: um reencontro com a pedagogia do oprimido. 7ạ ed. São Paulo: Paz e Terra; 2000. p. 206-207.

11. Oliveira LA, Landroni MAS, Kurokawa e Silva NE, Ayres JRCM. Humanização e cuidado: a experiência da equipe de um serviço de DST/Aids no município de São Paulo. Cien Saude Colet 2005; 10(3):689-698.

\section{Colaboradores}

PM Luz eJM C Teixeira participaram igualmente de todas as etapas da elaboração do artigo; $\mathrm{KCL}$ M iranda participou orientando a elaboração do artigo.
12. Ayres JRCM. Práticas educativas e prevenção de HIV/aids: lições aprendidas e desafios atuais. Interface (Botucatu) 2002; 6(11):11-24.

13. Pinheiro PNC, Vieira NFC, Pereira MLD, Teixeira BM G. $O$ cuidado humano: reflexão ética acerca dor portadores do HIV/aids. Rev. Latino-Am. Enfermagem [periódico na Internet]. 2005 jun-ago [acessado 2006 jan 12];13(4):[cerca de 7 p.] Disponível em: http://www.scielo.br/pdf/rlae/v13n4/v13n4a16.pdf

14. Freire P. Educação e mudança. $22^{a}$ ed. Rio de Janeiro: Paz e Terra; 1979.

15. Brasil. Ministério da Saúde. A conselhamento em DST/HIV/Aids para a Atenção básica. Brasília: M inistério da Saúde/Coordenação Nacional de DST e Aids; 2006.

16. Freire P. Pedagogia da autonomia: saberes necessários à prática educativa. São Paulo: Paz e Terra; 1996.

17. M claren P, Leonard P, Gadotti M. Paulo Freire: poder, desejo e memórias da libertação. Porto Alegre: Artmed; 1998.

18. Freitas ALSF. Pedagogia da conscientização: um legado de Paulo Freire à formação de professores. Porto Alegre: EdiPUCRS; 2001.

19. Damke IR. 0 processo do conhecimento na pedagogia da libertação. As idéias de Freire, Fiori e Dussel. Petrópolis: Vozes; 1995.

20. Freire P, Shor I. M edo e ousadia: o cotidiano do professor. Rio de Janeiro: Paz e Terra; 1986.

Artigo apresentado em 24/08/2007 Aprovado em 14/12/2007 